\title{
Veículo adaptado: caracterização de suas adaptaçóes e do perfil de seus condutores ${ }^{1}$
}

\author{
Marília Gabriela Azevedo de Resende ${ }^{a}$, Alessandra Cavalcanti ${ }^{b}$, Valéria Sousa de Andrade ${ }^{b}$ \\ aTerapeuta Ocupacional, Graduada, Universidade Federal do Triângulo Mineiro - UFTM, Uberaba, MG, Brasil \\ bProfessora Assistente I, Curso de Terapia Ocupacional, Pesquisadora, Laboratório Integrado de Tecnologia \\ Assistiva - LITA, Universidade Federal do Triângulo Mineiro - UFTM ,Uberaba, MG, Brasil
}

\begin{abstract}
Resumo: As adaptações veiculares proporcionam melhoria na funcionalidade da pessoa com deficiência, favorecendo autonomia, independência e equiparação nas oportunidades para "ir e vir". Este estudo objetivou caracterizar as adaptações veiculares e o perfil de seus condutores em um município do Triângulo Mineiro, no Estado de Minas Gerais. Realizou-se um embasamento conceitual sobre adaptações veiculares, acessibilidade e tecnologia assistiva, assim como a relação da Terapia Ocupacional com esses assuntos. O estudo caracteriza-se como uma pesquisa quantitativa exploratória e, enquanto procedimento metodológico, se configura como estudo de caso (casos múltiplos). Foram entrevistados 11 deficientes físicos que possuíam carros de passeio particular adaptados em circulação. Os resultados mostraram diferenciações quanto à localização da adaptação no veículo, aos locais de aquisição e instalação das adaptações, e aos modelos das adaptações, desde as realizadas artesanalmente até àquelas adquiridas comercialmente. Concluiu-se que houve variações nos modelos e que a maioria dos condutores procurou um meio alternativo para adquirir e instalar as adaptações, em vez de se valerem de empresas especializadas. Aponta-se a necessidade de serem conduzidos mais estudos que explorem esse campo.

Palavras-chave: Equipamentos de Autoajuda, Condução de Veículo, Saúde da Pessoa com Deficiência ou Incapacidade.
\end{abstract}

\section{Adapted vehicles: characterization of adaptations and profile of drivers}

\begin{abstract}
Automobile driving adaptations provide an improvement in the functionality of the person with physical disability, favoring the autonomy, independence and equalization of commuting opportunities. The purpose of this research was to characterize the automobile driving adaptations and the profile of drivers in a city in the State of Minas Gerais. The conceptual background on automobile driving adaptations, accessibility and assistive technology was studied, as well as the relation of occupational therapy with these themes. This is an exploratory quantitative research. It uses a case study (multiple cases) methodological procedure. Eleven disabled citizens who owned adapted leisure cars were interviewed. The results showed differentiations regarding the location of the adaptation in the automobile, the place of acquisition and installation of the adaptations and in the models of the adaptations - from the handcrafted to those commercially acquired. It was possible to conclude that there were variations in the models and that the majority of drivers tried an alternative way to acquire and install the adaptations, instead of the specialized companies. A necessity of more studies to exploit the field was verified.
\end{abstract}

Keywords: Self-help Devices, Automobile Driving, Health of the Disabled People.

Autor para correspondência: Alessandra Cavalcanti, Curso de Terapia Ocupacional, Unidade Centro Educacional - CE Universidade Federal do Triângulo Mineiro - UFTM, Av. Getúlio Guaritá, s/n, 3º Piso, Uberaba, MG, CEP 38025-440,

e-mail: lita@to.uftm.edu.br; mariliagabriela10@yahoo.com.br

Recebido: 9/2/2011; $1^{\mathrm{a}}$ Revisão: 2/12/2011; Aceite final: 20/12/2011. 


\section{Introdução}

No Brasil, os dados do Censo de 2000, realizado pelo Instituto Brasileiro de Geografia e Estatística (IBGE), indicaram que 24 milhóes e 600 mil pessoas possuem algum tipo de deficiência. Desse total, um milhão e oito mil e seiscentas pessoas têm deficiência física (INSTITUTO..., 2000).

Para pessoas com deficiência física, a mobilidade raramente é algo corriqueiro ou automático. Segundo Creel et al. (2005), andar, subir escadas, movimentar-se pela vizinhança e dirigir um carro são atividades tão costumeiras que a maioria das pessoas não as consideraria complexas. Contudo, uma deficiência física pode, por exemplo, impedir que uma pessoa use as pernas e/ou as máos para manejar os controles de veículos automotivos.

As adaptaçôes veiculares são consideradas pelo Governo Federal por meio do Decreto 5.296/2004 como um dos tipos de "ajuda técnica", que se define como sendo

[...] os produtos, instrumentos, equipamentos ou tecnologia adaptados ou especialmente projetados para melhorar a funcionalidade da pessoa portadora de deficiência ou com mobilidade reduzida, favorecendo a autonomia pessoal, total ou assistida. (LIMA, 2007, p. 226).

Assim, as adaptaçôes veiculares constituem-se como uma das formas de ajuda técnica ou equipamento de autoajuda, que permitem acessibilidade da pessoa com deficiência em automóvel particular, garantindo a equiparação de oportunidade para o "ir e vir", e que igualmente avalizam os princípios de dignidade e igualdade, fundamentados constitucionalmente pela União (BRASIL, 2006).

Para o terapeuta ocupacional, o "ir e vir" é uma das áreas de ocupação - atividades práticas ou instrumentais da vida diária,

[...] que são orientadas para a interação com o ambiente e que são frequentemente complexas - geralmente opcionais por natureza. (AMERICAN..., 2008, p. 631).

Dentre tais atividades, o terapeuta ocupacional caracteriza a "mobilidade na comunidade", a qual se define como sendo o

“[...] mover-se na comunidade e utilizar o transporte público ou privado, tais como dirigir um carro, ter acesso aos ônibus, táxis ou outros sistemas públicos de transporte". (AMERICAN..., 2008, p. 631).
O envolvimento nessas atividades apoia o indivíduo em um processo ativo no(s) contexto(s) do qual faz parte e desenvolve atividade e participação ao longo de sua vida (AMERICAN..., 2008). Esse envolvimento é referenciado como provedor de saúde e estados relacionados à saúde (ORGANIZAÇÃO PAN-AMERICANA...; ORGANIZAÇÃO MUNDIAL..., 2003).

Os terapeutas ocupacionais reconhecem que a saúde é apoiada e mantida quando os indivíduos são capazes de se envolverem em ocupaçôes e em atividades que permitam participação desejada ou necessária nos diferentes contextos como o da casa, da escola, do trabalho e de situaçóes na comunidade (AMERICAN..., 2008).

Para uma pessoa com deficiência física, a mobilidade na comunidade significa independência pessoal e profissional. Entretanto, a execução e a concretização dessa tarefa da vida prática perpassam primeiramente pelos princípios de acessibilidade para condução do próprio veículo. Para o deficiente físico, a dirigibilidade de um automóvel particular é intrinsecamente vinculada às possibilidades de adaptação e uso de equipamentos de autoajuda no carro (adaptaçóes veiculares/tecnologia assistiva) e de aquisição logística e financeira desses dispositivos.

A tecnologia assistiva (TA) permite o desempenho e a participação de pessoas em todas as áreas de suas vidas, e pode ser aplicada nos cuidados pessoais, no trabalho, na escola, no lazer e para a participação social (ÂNGELO; BUNING, 2005). Já uma adaptação é um ramo da TA e que se define como sendo uma modificação da tarefa, de um método e/ou do meio ambiente, promovendo independência e função. Adaptar promove ajuste, acomodação e adequação do indivíduo a uma nova situação, a uma nova tarefa que está sendo desenvolvida (TEIXEIRA; ARIGA; YASSUKO, 2003).

Assim, reconhecendo que o sistema de transporte público ou particular fornece às pessoas capacidade para se envolverem em atividades e papéis significativos (condutas que são esperadas pela sociedade e que podem prover direção na preferência e na escolha das ocupaçóes diárias) (AMERICAN..., 2008), tem-se que, para os indivíduos com deficiência física, há uma necessidade de adaptar funçôes de comando do veículo particular. As adaptaçóes devem ser efetivadas nos comandos de dirigibilidade (volante, acelerador, freio e/ou embreagem) dos utilitários convencionais para que a pessoa com deficiência possa conduzir seu veículo, obtendo de forma igualitária as condiçôes para a mobilidade na comunidade (ir e vir), assim como para desempenhar a tarefa de deslocamento usando o automóvel, compreendida 
pelo terapeuta ocupacional como uma atividade instrumental de vida diária, de maneira segura e confortável (CAVALCANTI et al., 2007).

Contudo, para que uma adaptação veicular seja efetivada, esta necessita estar em acordo com itens que incluam segurança, conforto, capacidade de independência, facilidade de manutenção e de operaçáo pelo usuário. Dessa forma, este trabalho buscou caracterizar as adaptaçóes veiculares e o perfil de seus condutores em um município do Triângulo Mineiro, fornecendo informações que auxiliem no entendimento de como ocorre a obtenção de dispositivos veiculares a partir da visão e da necessidade dos usuários.

\section{Percurso metodológico}

Este estudo foi classificado como uma pesquisa quantitativa exploratória e, enquanto procedimento metodológico, se configura em um estudo de caso; é considerado, aliás, um estudo de casos múltiplos, pois se estudou em conjunto mais de um caso para investigar o fenômeno da adaptação veicular (GIL, 2009).

A escolha da amostra representativa ou significativa deu-se pela amostragem por critério, a partir do contato com instituiçôes de uma cidade do Triângulo Mineiro, no Estado de Minas Gerais, que reabilitam pessoas com deficiência física. Como critério para inclusão na pesquisa, o sujeito deveria ter deficiência física, possuir carro de passeio adaptado e assinar o Termo de Consentimento Livre e Esclarecido entregue pela primeira autora no momento do contato inicial. Dessa forma, a população/amostra participante caracterizou-se por 11 pessoas com deficiência física que possuíam automóvel de passeio particular e que são condutores de veículos adaptados.

A coleta se deu nos meses de agosto e setembro de 2010, por meio de visitas domiciliares pré-programadas e com a devida autorização de seus correspondentes. Os dados foram obtidos mediante aplicação e preenchimento de um formulário simultaneamente a uma entrevista, seguida por observação espontânea do sujeito dirigindo seu carro adaptado. As entrevistas foram gravadas em meio digital, transcritas no formulário e submetidas à técnica de análise de conteúdo, do tipo análise categorial temática (BARDIN, 2010). Dessa análise, emergiram duas categorias, agrupadas de acordo com a similitude dos resultados, que refletem as características das adaptaçóes dos carros dos sujeitos participantes e o percurso para a efetivação das adaptaçóes.
Após a formulação do instrumento de coleta dos dados, realizou-se um teste piloto visando o aperfeiçoamento do formulário, verificando-se se as questôes ordenadas preenchiam ou não os objetivos da pesquisa. Em resposta ao teste piloto, foi acrescentada uma pergunta ao formulário, que relata o processo de instalação das adaptaçóes.

O projeto de pesquisa foi aprovado pelo Comitê de Ética da UFTM (CEP/UFTM) de acordo com o parecer $\mathrm{n}^{\circ} 1567$.

\section{Resultados e discussão}

Participaram deste estudo 11 sujeitos, sendo dez do gênero masculino e um do gênero feminino. A média de idade dos participantes foi de 50,2 anos, com variação entre 31 e 72 anos. A maioria dos entrevistados possui paraplegia como diagnóstico e uma minoria usa o membro afetado para controlar algum comando de dirigibilidade do veículo, isto é, possui movimento residual que é aproveitado no processo de direção veicular.

Quanto ao estado civil, seis sujeitos $(54,54 \%)$ são casados, quatro $(36,36 \%)$ são solteiros e um é $(9,1 \%)$ divorciado. Em relação ao grau de escolaridade, verificou-se ampla variação. Dos participantes, um $(9,09 \%)$ dos sujeitos não possui formação, mas demonstrou ser alfabetizado; dois $(18,18 \%)$ entrevistados possuem até o ensino primário; outro participante $(9,09 \%)$ exibiu o $1^{\circ}$ grau incompleto; dois condutores $(18,18 \%)$ possuem o $2^{\circ}$ grau incompleto; outros dois $(18,18 \%)$ relataram ter o $2^{\circ}$ grau completo; dois sujeitos $(18,18 \%)$ disseram ter escolarizaçáo superior incompleta, e apenas um (9,09\%) disse ter superior completo.

Dessa forma, percebe-se que a amostra atende às exigências do Departamento Nacional de Trânsito (DENATRAN) para a aquisição da carteira de habilitação no que diz respeito à alfabetização dos condutores (BRASIL, 2010).

Em relação à profissão desses condutores, cinco $(45,4 \%)$ sujeitos relataram ser aposentados; dois $(18,18 \%)$, atletas; um $(9,09 \%)$, instrutor de informática; um (9,09\%), microempresário; um $(9,09 \%)$, soldador, e um (9,09\%), professor. Assim, percebe-se que a maioria da amostra está inserida no mercado de trabalho e mantém um papel social.

No que se refere ao processo de habilitação, tem-se que dez $(90,9 \%)$ participantes possuem habilitaçáo para condição de deficiência e um (9,09\%) ainda não a havia adquirido. Dentre tais indivíduos, apenas quatro $(36,4 \%)$ percorreram o processo de habilitação na condição de deficiente. 
Caracterizando ainda os sujeitos participantes, verificou-se que nove possuem os membros inferiores totalmente afetados por uma deficiência, um possui ambos os membros afetados e um participante apresenta deficiência parcial nos membros inferiores (Tabela 1). Portanto, o dado corrobora com a literatura, que aponta que $90 \%$ dos motoristas com deficiência física que procuram serviços especializados para adaptar seus veículos automotores possuem um ou dois membros total ou parcialmente afetados (CAVALCANTI et al., 2007).

Com relação às características dos veículos adaptados dos participantes, em que se incluíram a marca, o ano de fabricação e o ano de aquisição, bem como o tipo de câmbio e de direçáo do veículo, verificou-se que os veículos possuíam uma ampla variação das marcas fabricantes e que a maioria deles tinha como ano de fabricação e de aquisição o período compreendido nesta última década. Os carros adaptados apresentaram distribuição aproximada entre os tipos de câmbio, a saber: automático $(54,5 \%)$ e manual $(45,4 \%)$. Uma pequena parte dos veículos apresentou direção convencional (27,3\%), tendo a maioria deles direção hidráulica $(72,7 \%)$. A Tabela 2 fornece um sumário das características dos veículos dirigidos pelas pessoas com deficiência.

Tabela 1. Características dos sujeitos participantes da pesquisa $(\mathrm{n}=11)$.

\begin{tabular}{|c|c|c|}
\hline Variável & Subgrupo & n $(\%)$ \\
\hline \multirow[t]{2}{*}{ Gênero } & Masculino & $10(90,9)$ \\
\hline & Feminino & $1(09,1)$ \\
\hline \multirow[t]{6}{*}{ Idade (em anos) } & $30-39$ & $5(45,4)$ \\
\hline & $40-49$ & $1(09,1)$ \\
\hline & $50-59$ & -- (-----) \\
\hline & $60-69$ & $4(36,4)$ \\
\hline & $70-79$ & $1(09,1)$ \\
\hline & Média $=50.2$ & \\
\hline \multirow[t]{6}{*}{ Profissão } & Aposentado & $5(45,4)$ \\
\hline & Atleta & $2(18,2)$ \\
\hline & Instrutor de informática & $1(09,1)$ \\
\hline & Micro - empresário & $1(09,1)$ \\
\hline & Soldador & $1(09,1)$ \\
\hline & Professor & $1(09,1)$ \\
\hline \multirow[t]{3}{*}{ Estado Civil } & Casado & $6(54,5)$ \\
\hline & Solteiro & $4(36,4)$ \\
\hline & Divorciado & $1(09,1)$ \\
\hline \multirow[t]{7}{*}{ Escolaridade } & Alfabetizado & $1(09,1)$ \\
\hline & Primário & $2(18,2)$ \\
\hline & $1^{\circ}$ grau incompleto & $1(09,1)$ \\
\hline & $2^{\circ}$ grau incompleto & $2(18,2)$ \\
\hline & $2^{\circ}$ grau completo & $2(18,2)$ \\
\hline & Superior incompleto & $2(18,2)$ \\
\hline & Superior completo & $1(09,1)$ \\
\hline \multirow[t]{3}{*}{ Membro afetado } & Ambos os membros inferiores (MMII) & $9(81,8)$ \\
\hline & Ambos MMII e MMSS parcialmente & $1(09,1)$ \\
\hline & Apenas um membro inferior & $1(09,1)$ \\
\hline \multirow[t]{4}{*}{ Tipo de deficiência } & Paraplegia & $7(63,6)$ \\
\hline & Tetraparesia & $2(18,2)$ \\
\hline & Osteogênese imperfeita & $1(09,1)$ \\
\hline & Seringomielocele & $1(09,1)$ \\
\hline \multirow[t]{2}{*}{ Uso do membro afetado para dirigir } & Sim & $2(18,2)$ \\
\hline & Não & $9(81,8)$ \\
\hline \multirow[t]{2}{*}{ Habilitação } & Sim & $10(90,9)$ \\
\hline & Não & $1(09,1)$ \\
\hline
\end{tabular}


Tabela 2. Características dos veículos $(\mathrm{n}=11)$.

\begin{tabular}{ccc}
\hline Variável & Subgrupo & $\mathbf{n ~ ( \% )}$ \\
\hline Marca & Citröen & $1(09,1)$ \\
& Chevrolet & $1(09,1)$ \\
& Fiat & $1(09,1)$ \\
& Ford & $1(09,1)$ \\
& Honda & $1(09,1)$ \\
& Peugeot & $1(09,1)$ \\
& Volkswagen & $2(18,2)$ \\
& Toyota & $3(27,3)$ \\
\hline Ano de fabricação & $80-1989$ & $2(18,2)$ \\
& $90-1999$ & $3(27,3)$ \\
& $00-2009$ & $6(54,5)$ \\
\hline Ano de aquisição & $80-1989$ & $1(09,1)$ \\
& $90-1999$ & $--(----)$ \\
& $00-2009$ & $10(90,9)$ \\
\hline Câmbio & Automático & $6(54,5)$ \\
& Manual & $5(45,4)$ \\
\hline Direção & Convencional & $3(27,3)$ \\
& Hidráulica & $8(72,7)$ \\
\hline
\end{tabular}

Ao se pontuar a marca dos veículos, se observou que todos os fabricantes possuem programa de inclusão, restringindo-se suas informações apenas ao processo de aquisição de seus veículos com isenção de impostos. A escolha por determinada marca envolve habilidade motora para dirigir, como, por exemplo, postura, coordenação, força e fatores intrínsecos relacionados ao veículo (tamanho do carro, habilidade para entrar e sair do carro e facilidade para se mover no assento) (ARBESMAN; PELLERITO JUNIOR, 2008).

Os resultados referentes à primeira categoria de análise - Características das adaptaçôes dos veículos - englobaram questôes relacionadas à localização da adaptação no veículo (acelerador, freio ou embreagem), local de aquisiçấo do dispositivo (empresa especializada ou outro) e local responsável pela instalação (empresa especializada ou outro) (Tabela 3).

A questão referente à localização das adaptações nos veículos apresentou, nesta pesquisa, quatro possibilidades de adaptaçáo dos equipamentos de controle, sendo proporcional entre os veículos a localização entre os comandos de acelerador/freio/ embreagem $(36,4 \%)$ e acelerador/freio/volante (36,4\%). As demais adaptaçóes de controle foram acelerador/freio (18,2\%) e freio/embreagem $(9,1 \%)$.

Segundo Cavalcanti e colaboradores (2007), os equipamentos padronizados são os fabricados em série, utilizados para atender às deficiências mais comuns, e estâo disponíveis para a compra no mercado. Os equipamentos especiais são os fabricados para atender às necessidades particulares de uma pequena parte das pessoas com deficiência, são específicos e dificilmente poderão ser utilizados para outros candidatos.

A classificação adotada neste estudo difere-se da descrita acima. Definiu-se como equipamentos padronizados aqueles fornecidos por empresas especializadas e como equipamentos especiais, aqueles criados pelos próprios usuários ou outros. A maioria dos entrevistados teve experiências diferentes que influenciaram suas adaptaçóes; portanto, no que se refere ao local de aquisição da adaptação, a maioria dos condutores $(63,6 \%)$ relatou ter adquirido as adaptaçôes nomeadas como equipamentos especiais e uma minoria $(36,4 \%)$ adquiriu equipamentos padronizados (por meio de empresas especializadas).

Ressalta-se que o processo pelo qual os usuários percorreram para adquirir suas adaptaçóes pode estar relacionado com as experiências vividas por eles, pois cursaram caminhos condizentes com suas realidades culturais, financeiras, sociais e de contextos arquitetônicos.

Ainda, com relação ao local de realização da instalação do dispositivo adaptado, verificou-se que a mesma característica se manteve. Ou seja, a maioria dos condutores $(54,6 \%)$ teve como profissionais responsáveis pela instalação das adaptações em seus veículos profissionais liberais, como mecânicos, soldadores e serralheiros. As empresas especializadas foram relatadas como uma opção de poucos sujeitos participantes $(45,4 \%)$. Esse quadro pode ser explicado pelo fato de que o processo de decisão sobre qual modelo de adaptação é o ideal para a necessidade do condutor é complexo, à medida que incorpora segurança, estilo e custo/benefício, o que é corroborado por Arbesman e Pellerito Junior (2008).

Dessa forma, a discussão sobre quem concebe, cria e instala o equipamento adaptado concerne à facilidade de uso e conforto na operação deste, que perpassa pelas habilidades do condutor (ARBESMAN; PELLERITO JUNIOR, 2008). Tal iniciativa pode vir a justificar a incidência de 54,6\% dos entrevistados terem recorrido a profissionais liberais, não envolvidos no ramo de adaptaçôes veiculares, em vez de se remeterem às empresas especializadas.

Acrescenta-se que as características de cada adaptação decorrem de exame clínico, pelo laudo médico que atesta as habilidades remanescentes do indivíduo e pela experiência própria do usuário.

Com relaçáo aos tipos de equipamentos, verificou-se que os carros dos participantes possuíam 
Tabela 3. Características das adaptações dos veículos ( $\mathrm{n}=11)$.

\begin{tabular}{llc}
\hline \multicolumn{1}{c}{ Variável } & \multicolumn{1}{c}{ Subgrupo } & n (\%) \\
\hline Localização da adaptação no veículo & Acelerador, freio e embreagem & $4(36,4)$ \\
& Acelerador, freio e volante & $4(36,4)$ \\
& Acelerador e freio & $2(18,2)$ \\
& Freio e embreagem & $1(09,1)$ \\
\hline Local de aquisição da adaptação e & Empresa especializada & $4(36,4)$ \\
responsável por sua instalação & Oficina mecânica & $3(27,3)$ \\
& Próprio usuário & $2(18,2)$ \\
& Serralheiro & $1(09,1)$ \\
& Torneiro mecânico & $1(09,1)$ \\
\hline
\end{tabular}

os comandos de dirigibilidade posicionados em lugares diferentes e em configurações distintas. Foram catalogados cinco tipos de equipamentos junto à amostra e percebeu-se que todos tinham como essência do mecanismo algum tipo de alavanca.

Portanto, 18,2\% da amostra apresentou adaptação em alavanca no vão interno do veículo, no espaço que existe entre o câmbio e a perna direita do motorista. Nestes tipos de adaptação, a alavanca tem a função de possibilitar o acionamento manual dos comandos de dirigibilidade para embreagem (alavanca deve ser empurrada para baixo), frenagem (alavanca deve ser empurrada contra o painel do veículo) e aceleraçáo (alavanca deve ser girada no sentido horário).

O segundo tipo de adaptação verificada (27,3\%) englobava os comandos para o freio, o acelerador e a direção (volante). Da mesma forma que a adaptação anterior, trata-se de uma alavanca no espaço entre o câmbio e a perna direita com a funçáo de frear (alavanca deve ser empurrada contra o painel do veículo) e acelerar (alavanca deve ser puxada em direção ao motorista), tendo sido observada ainda instalação de pomo no volante.

O pomo corresponde a um equipamento que é fixado no volante e que tem como função auxiliar no mecanismo de uso/preensão do comando, facilitando o giro (deslocamento) deste pelo motorista que possui limitação motora para fazê-lo. São indicados para usuários com limitaçóes nos movimentos de preensão da mão e extensão e flexáo de punho, estando disponíveis no mercado nos tipos: pomo de dois pontos, pomo de três pontos e pomo giratório (CAVENAGHI, 2010). Nesta pesquisa, foram observados pomo do tipo giratório e do tipo de três pontos, numa proporção 27,3 e 09,1\% respectivamente.

A maior parte das adaptaçóes identificadas estava relacionada à frenagem e à aceleraçáo (36,4\% dos veículos) e são conhecidas no mercado como "sistema puxa-empurra", que consiste em uma alavanca posicionada atrás do volante, com empunhadura para frenagem e aceleração, sobressaindo à esquerda ou à direita. Dentre esse percentual, 9,1\% dos veículos possuíam também automação da embreagem, isto é, automatização do funcionamento da embreagem por meio de um sensor. O "sistema puxa-empurra" é descrito na literatura como sendo o mais utilizado no Brasil e na América Latina; funcionalmente, permite que o condutor acelere o veículo puxando a empunhadura em direção ao volante e o freie empurrando-a contra o painel (CAVALCANTI et al., 2007).

Um veículo $(9,1 \%)$ possuía adaptação com três alavancas individualizadas para os comandos de embreagem, freio e aceleração, enquanto outro $(9,1 \%)$ possuía apenas uma única alavanca para acionar a embreagem e mudar a marcha do veículo. Esse carro apresentava também prolongamento do pedal do freio.

Com relação à segunda categoria - Percurso para efetivação das adaptaçōes -, registrou-se que a maioria das pessoas com deficiência participantes deste estudo $(45,4 \%)$ observou adaptaçóes de pessoas conhecidas e, em seguida, procuraram um serviço alternativo de pessoal técnico em serralheria, mecânica ou tornearia mecânica. Dentre esses participantes, apenas um único sujeito seguiu as indicaçóes prescritas no laudo do Departamento de Trânsito de Minas Gerais (DETRAN/MG) (Tabela 4).

As empresas especializadas foram opção de 36,4\% da amostra estudada. Dentre tais indivíduos, dois sujeitos $(18,2 \%)$ seguiram na íntegra as indicaçôes quanto aos tipos de adaptaçóes determinadas pelo DETRAN/MG. Os sujeitos restantes desta amostra tiveram contato com lojas do ramo e feiras de reabilitaçáo tecnológica, para então adquirirem suas adaptaçóes em empresas especializadas. Houve, ainda, confecção artesanal na própria residência de respondentes da pesquisa $(18,2 \%)$. 
Tabela 4. Caracterização do percurso do usuário para efetivação das adaptações $(\mathrm{n}=11)$.

\begin{tabular}{lc}
\hline \multicolumn{1}{c}{ Percurso para aquisição das adaptações } & n (\%) \\
\hline $\begin{array}{l}\text { Usuário observou adaptação de conhecido e procurou serviço alternativo } \\
\text { (serralheiro, mecânico ou torneiro mecânico) Seguiu as indicações do laudo }\end{array}$ & $5(45,4)$ \\
DETRAN/MG = $1(09,1)$ & $4(36,4)$ \\
\hline Usurário adquiriu adaptação em empresa especializada Seguiu as & \\
indicações do laudo DETRAN/MG = 2 (18,2) Outros (feira, loja) $=2(18,2)$ & $2(18,2)$ \\
\hline Usuário confeccionou adaptação artesanalmente em casa &
\end{tabular}

\section{Considerações finais}

O estudo apresentou as características das adaptaçôes e o perfil de seus condutores, sujeitos com deficiência física, em uma cidade do Triângulo Mineiro. Houve, como fatores limitantes, o restrito acervo bibliográfico referente ao tema e o tamanho da amostra, de maneira que os achados náo podem ser generalizados e aplicados a todos os casos de veículo adaptado.

Os resultados sugeriram que os condutores são em sua maioria do gênero masculino, diagnosticados com paraplegia e com média de idade de 50,2 anos. Os carros adaptados apresentaram ampla variaçáo das marcas e, a maior parte, com ano de fabricação e aquisição na última década.

No que se refere à localização da adaptação no veículo, os comandos para dirigibilidade foram para acelerador, freio, embreagem e volante. Quanto ao local de aquisição e de instalação da adaptação, registrou-se que a maioria dos condutores procurou meio alternativo em vez de procurar empresas especializadas no ramo de adaptação de veículos para pessoas com deficiência física.

Sugerem-se futuros estudos sobre o tema proposto, levando-se em conta ampliação da amostra, qualificação de como o processo de aquisiçáo ocorre e entendimento do assunto a partir da visáo de fabricantes, dos órgãos competentes e do próprio usuário.

Conclui-se que os carros convencionais tornam-se cada vez mais refinados e automatizados, características essas que conferem segurança e conforto aos usuários, além de que as adaptações veiculares acrescentam para a pessoa com deficiência autonomia, manutençáo da independência para mobilidade em contextos da comunidade e seu retorno no envolvimento de ocupaçóes. Portanto, essas questôes comprovam a importância da elucidação dos fenômenos abordados neste estudo, bem como de todo o processo e os fatores envolvidos sobre tecnologia assistiva/adaptaçôes veiculares.

\section{Referências}

AMERICAN OCCUPATIONAL THERAPY ASSOCIATION - AOTA. Occupational Therapy Practice - Framework: Domain \& Process. The American Journal Occupational Therapy, v. 62, n. 9, p. 625-683, 2008. ÂNGELO, J.; BUNING, M. E. Adaptaçōes de Alta Tecnologia para Compensar a Deficiência. In: TROMBLY, C. A.; RADOMSKI, M. V. Terapia Ocupacional para as Disfunçôes Físicas. 5. ed. São Paulo: Santos, 2005. p. 389-420.

ARBESMAN, M.; PELLERITO JUNIOR, J. P. EvidenceBased perspective on the effect of automobile-related modifications on the driving ability, performance, and safety of older adults. American Journal of Occupational Therapy, v. 62, n. 2, p. 173-186, 2008. PMid:18390011. http://dx.doi.org/10.5014/ajot.62.2.173

BARDIN, L. Análise de Conteúdo. Lisboa: Ediçōes 70, 2010.

BRASIL. Constituição (1988). Constituição da República Federativa do Brasil: Texto constitucional promulgado em 5 de outubro de 1988, com as alteraçóes adotadas pelas Emendas Constitucionais no $1 / 92$ a 52/2006 e pelas Emendas Constitucionais de Revisão no 1 a 6/94. Brasília: Senado Federal, Subsecretaria de Ediçōes Técnicas, 2006. $88 \mathrm{p}$.

BRASIL. Departamento Nacional de Trânsito - DENATRAN. Disponível em: <http://www. denatran.gov.br/>. Acesso em: 20 nov. 2010.

CAVALCANTI, A. et al. Adaptação Veicular. In: CAVALCANTI, A.; GALVĀO, C. Terapia Ocupacional: fundamentação e prática. Rio de Janeiro: Guanabara Koogan, 2007. p. 473-479.

CAVENAGHI. Linha Direção. Disponível em: <http:// www.cavenaghi.com.br/O-que-fazemos $/ ? \mathrm{i}=2 \& s=6>$. Acesso em: 20 nov. 2010.

CREEL, T. A. et al. Mobilidade. In: PEDRETTI, L. W.; EARLY, M. B. Terapia Ocupacional: capacidades práticas para as disfunçôes físicas. 5. ed. São Paulo. Roca, 2005. p. $184-225$

GIL, A. C. Estudo de Caso. São Paulo: Atlas, 2009.

INSTITUTO BRASILEIRO DE GEOGRAFIA E ESTATÍSTICA - IBGE. Tendências Demográficas no Período de 1950-2000. Brasília: IBGE, 2000. Disponível em: <http://www.ibge.gov.br/home/estatistica/populacao/ censo2000/tendencias_demograficas/comentarios.pdf>. Acesso em: 20 nov. 2010. 
LIMA, N. M. Pessoa Portadora de Deficiência - Legislação Federal Básica. Brasília: SEDH, Coordenadoria Nacional para Integração da Pessoa Portadora de Deficiência, 2007 ORGANIZAÇÃO PAN-AMERICANA DA SAÚDE - OPAS; ORGANIZAÇÃO MUNDIAL DA SAÚDE - OMS. Classificação Internacional de
Funcionalidade - CIF: incapacidade e saúde. São Paulo: EdUSP, 2003.

TEIXEIRA, E.; ARIGA, M. Y; YASSUKO, R. Adaptações. In: TEIXEIRA, E. et al. Terapia Ocupacional na reabilitação física. São Paulo: Roca, 2003. p. 129-174.

\section{Contribuição dos Autores}

Marília Gabriela Azevedo de Resende: elaborou o projeto de pesquisa, coletou e analisou os dados e redigiu o manuscrito. Alessandra Cavalcanti: orientou o desenvolvimento do projeto de pesquisa, incluindo coleta e análise de dados e, orientou a redação do artigo, assim como realizou a revisão do manuscrito. Valéria Sousa de Andrade: realizou a revisão do manuscrito.

\section{Notas}

${ }^{1}$ Resultado do Trabalho de Conclusão de Curso (TCC) do Curso de Terapia Ocupacional da Universidade Federal do Triângulo Mineiro - UFTM - aprovado pelo Comitê de Ética em Pesquisa em Seres Humanos da UFTM de acordo com o parecer no 1567. 